\title{
A Syntax-based Analysis of Predication
}

\author{
Claire Beyssade \& Carmen Dobrovie-Sorin \\ Institut J. Nicod - CNRS \\ Laboratoire de Linguistique Formelle - CNRS Paris 7
}

Adjectives and common nouns are currently assigned the same semantic analysis: both categories are said to denote sets of individuals (type $\langle e, t>$ ). We will show that this assumption is empirically inadequate and we will assume instead that adjectives denote properties (viewed as primitive entities, not as sets of individuals) instantiated in individuals, whereas (number marked) common nouns basically denote sets of individuals. Correlated with this distinction, we will propose the existence of two distinct rules of predication: (i) an entity is a member of a set of entities and (ii) a property is localized in an entity. Our analysis is based on the Aristotelian view that has become the basic postulate of property theory (Chierchia 1982, 1985, Chierchia and Turner 1988, Fox 2000), namely the existence of two basic types of entities: individuals and properties or, as Chierchia puts it, 'predicable and non predicable individuals'. Our empirical investigation will cover a wide range of phenomena: (i) the different syntactic distribution of adjectives, bare NPs, and Number Phrases (NumPs); (ii) the contrast between ce and il/elle 'he/she' in French; (iii) the behavior of names of profession in Romance copula sentences, which will be extended to bare NPs of the type fils d'avocat 'son of lawyer' and ami (avec Pierre) 'friend (with Pierre)'; (iv) the contrast between bare plurals and bare singulars.

\section{Nominal vs. Adjectival Predicates}

The classical hypothesis that adjectives and common nouns share the same type of denotation predicts that (i) adjectives can appear in those argument positions in which common nouns can be bare, and (ii) common nouns consistently appear bare in predicate position. Both predictions are contradicted by the data:

(1) a. I saw students.

b. *I saw blue / $*$ I ate hot.

(2) a. There are apples on the table.

b. *There is $\{$ blue, soft, hot $\}$ on the table.

(3) a. John is handsome.

b. *John is boy.

\subsection{Two Types of Predicates}

In this paper we will argue that the contrasts between the distribution of (sortal) nouns and adjectives can be understood only if we distinguish two types of oneplace predicates, which are both of type $\langle e, t\rangle$, but crucially differ regarding the 
way in which the argument position is saturated: sortal nominal predicates can be defined as extensional properties or 'qua-sets' predicates, whereas adjectival predicates are intensional properties, or 'qua-property' predicates. More precisely, we will assume that to each adjective Adj is associated a corresponding property $P_{A d j}$, which is attributed to an entity. To take an example, we will analyze nominal predicates and adjectival predicates as follows:
a. [NPboy] denotes the set of boys
b. [Adjp handsome] translates as 'have $\mathrm{P}_{\text {handsome' }}$

Our proposal assumes the basic postulate of property theory, namely the idea that properties cannot be reduced to sets of individuals, but rather they constitute a particular type of entity. Chierchia (1985) gave some evidence that speakers are committed to the existence of properties:
a. Chris has [DPthe property of being happy].
b. Chris exemplifies [NP happiness].
c. John is everything $g_{i}$ his mother wanted him to be $e_{i}$.

In (5a-b), the speaker directly attributes a property to an individual, and in (5c), the speaker quantifies over properties.

Moreover, natural language allows us to predicate properties of properties, (e.g., red is a colour) or to express our attitudes regarding properties, as in John likes red. In examples of this type, properties have the same role as particular individuals, the paradigmatic case of entities. As Larson and Segal (1995: 142143) remind us, the existence of properties is also strongly suggested by certain well-known observations: one can know the intended meaning of a property without being acquainted with those objects that have that property; furthermore, there are many examples of properties that are distinct, and nevertheless have the same extension.

\subsection{Nominal Projections: the Functional Category of Number and Set- Denotation}

Let us now examine somewhat more attentively the syntactic make-up of nominal expressions. Note first that (4a) is not precise enough. As shown in (3b), singular countable nouns cannot be used bare, but they must be accompanied by the indefinite article, even in predicate positions. Given the quite standard assumption that the singular indefinite article is the realization of Number, the ungrammaticality of $(3 b)$ indicates that the projection of the functional category of Number ${ }^{1}$ is necessary for sortal common nouns. This syntactic requirement can be explained as being due to (i) a correlation between the projection of the functional category of Number and set-denotation and (ii) the semantic properties of sortal nouns: they can never function as qua-property predicates, but are instead designed to be extensionalized, which - given the correlation stated in (i) forces the projection of Number. To put it more explicitely, when picked up from 
the Lexicon, bare sortal nouns denote properties of objects (or of kinds), but the property-denotation of sortal nouns does not survive in the syntax. In other words, sortal nouns cannot be saturated 'from the outside', by a truly 'external argument', i.e., a constituent that is outside the nominal projection itself; instead, the argument position of sortal nouns must be bound by Number, and NumPs function as qua-sets predicates, i.e., they denote sets of entities (atomic individuals, groups, or quantities of matter). We should then restate (4a) as (6a-b); (6c-d) are added in order to make explicit the analysis of bare plurals and bare mass nouns:
a. [ ${ }_{\mathrm{NP}}$ boy] denotes the property (viewed as a function and not as an entity) of being a boy, i.e., $\lambda x$ boy (x)
b. $\left[_{\mathrm{NumP}}[\mathrm{a}]_{\mathrm{NP}}[\right.$ boy $]$ denotes the set of boys, i.e., $\{\mathrm{x}$, boy $(\mathrm{x})\}$
c. $\left[_{\mathrm{NumP}}\left[\mathrm{Plur}_{\mathrm{N}} \varnothing\right]\right.$ [NP $\left._{\mathrm{NP}} \mathrm{boys}_{\mathrm{pl}}\right]$ ] denotes the set of groups of boys, i.e. $\{\mathrm{X}$ : boys $(\mathrm{X})\}$ (capital letters notate group variables)
d. [quantP $\left[s_{g} \varnothing\right]\left[{ }_{N P}\right.$ butter] $]$ denotes the set of quantities of matter that are butter, i.e., $\{x$ : butter $(x)\}$

Summarizing, singular indefinite countables, bare plurals and bare mass nouns are to be analyzed as syntactic constituents labeled NumP and as correlatively denoting sets of entities. This type of constituent can function as a maximal projection of the noun, occurring in predicate positions as well as in certain argument positions, as shown in (7a-c) and (7a'-c'), respectively: ${ }^{2}$
a. John is a boy.
a'. I saw a boy.
b. John and Mary are students.
b'. I saw students.
c. This is gold.
c'. I love gold.

NumPs can also form a subconstituent of the maximal N-projection, in those cases where they are embedded under Det:

$$
\text { a. [DP this } \left.\left.\left[_{N u m P} \emptyset\left[{ }_{N P} \text { horse }\right]\right]\right] \text { b. [DP } \text { these }\left[{ }_{N u m P} \mathrm{pl}\left[{ }_{N P} \text { horses }\right]\right]\right]
$$

In sum, sortal (object-denoting) nouns constitute the paradigmatic type of nominal predicates. Their core characteristic is that they cannot appear bare in predicate position, but are necessarily accompanied by the singular indefinite article. This behavior was analyzed above as being due to the fact that sortal nouns cannot denote intensional properties, but instead must be extensionalized into sets of individuals, a type of denotation that necessarily corresponds to the syntactic category of NumP. In section 1.4. below, we will see that relational nouns behave differently.

\subsection{Adjectival Predicates}

Following Baker (2003), we assume that adjectives do not project any functional category. Rather, they inherit Number (and Gender) via the Agreement relation. 
Given (i) the correlation assumed above between the functional category of Number and set-denotation, and (ii) the fact that adjectives cannot be governed by Number, adjectives should be unable to denote sets of individuals. We will assume instead that adjectives are to be analyzed as qua-property predicates, i.e., predicates that denote properties possessed by or instantiated in entities. Correlatively, adjectives are predicates which can only be saturated from outside their syntactic category. In sum, adjectives and sortal nouns consistently differ in both syntactic category and type of denotation: obligatory lack $v s$. obligatory presence of Number correlates with property-denotation vs. set-denotation. NumPs denote sets of entities, and APs denote properties instantiated in entities.

We will analyze adjectives in predicate position as in (9b):

a. Jean est orgueilleux. 'Jean is proud'

b. (est) orgueilleux $=$ has the property of being proud

In French, some adjectives can be nominalized, both in argument position and in predicate position. For examples of this type, a change in syntactic category, from adjectives to nouns, is currently assumed. On a par with nouns, such nominalized adjectives can be governed by Num:

(10) a. Un orgueilleux m'a insulté hier. a proud me has insulted yesterday 'a proud man insulted me yesterday'

b. Jean est un orgueilleux.

Jean is a proud 'Jean is a proud man'

\subsection{Relational Nouns}

The projection of Num is not necessary for nouns in general, but only for a subclass of nouns, sortal nouns. Sortal nouns are characterizable by an identity condition (Geach 1962, Larson and Segal 1995), that determines whether two individuals constitute the same or different individuals.

the same man / the same number / the same water

Unlike sortal nouns, relational nouns can be used bare, i.e., without an indefinite article, in French (and the other Romance languages):
Jean est ami avec Pierre.
Jean is friend with Pierre
'Jean is a friend of Pierre'

The examples in (13) show that relational nouns can be used not only bare, but also be accompanied by the indefinite article. But quite interestingly, the presence vs. absence of article correlates with a difference in the type of complement: 
relational nouns can be saturated either inside the $\mathrm{N}$-projection (with a Genitive DP) or outside it (with a PP).
a. Jean est $\left\{{ }^{*}\right.$ ami de Pierre, un ami de Pierre $\}$. Jean is $\{$ friend of Pierre, a friend of Pierre\}
b. Jean est \{ami avec Pierre, * un ami avec Pierre\}. Jean is \{friend with Pierre, a friend with Pierre\} 'Jean is a friend of Pierre'

The correlation between the presence vs. absence of article and the type of complement holds not only for the predicate position, but also for argument positions:
a. $\left\{U n, L^{\prime}\right\}$ ami de Pierre est venu hier.
' $\{\mathrm{A}, \mathrm{The}\}$ friend of Pierre came yesterday'
b. $\quad\left\{{ }^{*} \mathrm{Un},{ }^{*} \mathrm{~L}^{\prime}\right\}$ ami avec Pierre est venu hier.
' $\{$ A, The $\}$ friend with Pierre came yesterday'

To sum up, relational nouns built with PPs behave on a par with adjectives and verbs and contrast with sortal nouns, whereas relational nouns built with Genitive DPs side with sortal nouns.

\section{Two Distinct Rules of Predication}

In what follows we will examine a well-known but still mysterious constraint on the distribution of the subject pronoun $c e^{3}$ in French. Our account will be based on the idea that copula sentences rely on two distinct rules of predication, depending on whether the predicate is an adjective, i.e., a qua-property predicate, or a number-marked noun, i.e., a qua-set predicate.

\subsection{Ce vs. il in French}

The paradigm in (15)-(16) illustrates an interesting correlation that holds in French copula sentences (a.o., Kupferman 1979, Pollock 1983, Boone 1987, Laca and Tasmowski 1994, Roy 2001, Matushansky and Spector 2004, de Swart et al. 2004), between the type of subject pronoun (il/elle 'he/she' vs. ce) and the type of predicate (adjectival predicate $v s$. nominal predicate):

(15) a. Marie est entrée. Elle était belle.

'Mary entered the room. She was good-looking'

a'. ?? Marie est entrée. Elle était une belle femme.

'Mary entered the room. She was a good-looking woman'.

b. * Marie est entrée. C'était belle.

'Mary entered the room. She (CE) was good-looking'

b'. Marie est entrée. C'était une belle femme. 
(16)

'Mary entered the room. She (CE) was a gd-looking woman'

a. Marie, elle était belle.

'Mary, she was good-looking'

a'. ?? Marie, elle était une belle femme.

'Mary, she was a good-looking woman'

b. * Marie, c'était belle.

'Mary, she (CE) was good-looking'

b'. Marie, c'était une belle femme.

'Mary, she (CE) was a good-looking woman'

The pattern shown in (15)-(16) also holds for anaphoric ce when it refers to quantities of matter:

(17) a. Regarde le beurre, il est \{mou, *de l'eau\}.

'Look at the butter, it is $\{$ soft, water\}'

b. Regarde le beurre, c'est $\{$ de l'eau, *mou\}.

'Look at the butter, CE is $\{$ water, soft $\}$ '

The examples in (15b)-(17b) point to the generalization stated in (18):

(18) Anaphoric ce cannot be used with adjectival predicates, ${ }^{4}$ but only with nominal predicates.

Personal pronouns are subject to the inverse requirement, which is however less strict (as indicated by the two question-marks, instead of the star): when the subject is a personal pronoun, the use of an adjectival predicate is preferred, but nominal predicates are however not completely unacceptable.

\subsection{Two Rules of Predication}

According to the hypothesis proposed in section 1, the distinction in grammatical category between adjectives and nouns correlates with a difference in denotation, between properties and sets of individuals. In what follows we will propose that this difference correlates with a difference between two distinct rules of predication.

Different theories of predication - in particular set-theory and propertytheory - are available, which are generally thought of as alternative models, which may be used to represent any kind of predicate. We will propose instead that both analyses of predication are needed, the choice of one or the other depending on the type of predicate. Restricting our attention to copula sentences, we will propose that the set-theoretic and the property-theoretic rules of predication respectively correspond to copula sentences built with nominal (or more precisely NumPs, i.e., nouns governed by Number) and adjectival predicates: a property (associated with an adjective) is attributed to an individual or an individual is said to belong to a set (denoted by a Number-marked noun). 
Let us first consider the set-theoretic rule of predication, which we assume to correspond to NumP-predicates.

\section{Classif ying Predication}

$$
[[[\mathrm{DP} \text { is } \mathrm{NumP}]]=1 \text { iff }[[\mathrm{DP}]] \in[[\mathrm{NumP}]]
$$

For illustration, let us consider the sentence in (20). The steps of the compositional computation, given in (21), are similar to what one finds in Montagovian grammars.

(20) John is a man.

(21) $[[$ John $]=\lambda P P(j) \quad[[$ man $]]=M$

$[[\mathrm{a}]]=\lambda \mathrm{P} \lambda \mathrm{Q} \exists \mathrm{x}(\mathrm{P}(\mathrm{x}) \wedge \mathrm{Q}(\mathrm{x}))$

$[[$ a man] $]=\lambda P \lambda Q \exists x(P(x) \wedge \mathrm{Q}(\mathrm{x})) . \mathrm{M}=\lambda \mathrm{Q} \exists \mathrm{x}(\mathrm{M}(\mathrm{x}) \wedge \mathrm{Q}(\mathrm{x}))$

$[[$ is $]]=\lambda X \lambda x X(\lambda y \quad(x=y))$

$[$ [is a man]] $=\lambda X \lambda x X(\lambda y(x=y)) \cdot \lambda Q \exists z(M(z) \wedge Q(z))$

$=\lambda \mathrm{x} \lambda \mathrm{Q} \exists \mathrm{z}(\mathrm{M}(\mathrm{z}) \wedge \mathrm{Q}(\mathrm{z}))(\lambda \mathrm{y}(\mathrm{x}=\mathrm{y}))$

$=\lambda \mathrm{x} \quad \exists \mathrm{z}(\mathrm{M}(\mathrm{z}) \wedge(\lambda \mathrm{y}(\mathrm{x}=\mathrm{y}))(\mathrm{z}))=\lambda \mathrm{x} \quad \exists \mathrm{z}(\mathrm{M}(\mathrm{z}) \wedge(\mathrm{x}=\mathrm{z}))$

$[[\mathrm{John}$ is a man] ] $=\lambda \mathrm{P} P(\mathrm{j}) \cdot \lambda \mathrm{x} \quad \exists \mathrm{z}(\mathrm{M}(\mathrm{z}) \wedge(\mathrm{x}=\mathrm{z}))$

$$
=\lambda \mathrm{x} \quad \exists \mathrm{z}(\mathrm{M}(\mathrm{z}) \wedge(\mathrm{x}=\mathrm{z})) \mathrm{j}=\exists \mathrm{z}(\mathrm{M}(\mathrm{z}) \wedge(\mathrm{j}=\mathrm{z}))=\mathrm{M}(\mathrm{j})
$$

If we adopt an explicitly set-theoretic notation, we have (22):

$$
\begin{aligned}
& {[[\mathrm{a} \text { man }]]=\{\mathrm{x}: \mathrm{x} \text { is } \mathrm{a} \operatorname{man}\} \quad[[\mathrm{John}]]=\mathrm{j}} \\
& {[[\mathrm{John} \text { is a man }]]=1 \text { iff }[[\mathrm{John}]] \in[[\mathrm{a} \text { man }]]} \\
& \text { iff } \mathrm{j} \in\{\mathrm{x}: \mathrm{x} \text { is a man }\}
\end{aligned}
$$

We would like to stress the role of the indefinite article $a$, viewed here as a realization of Number. This functional category is responsible for the change in denotation of the common noun man, from a property constant, to a set of individuals. In other words, we can say that $a$ man denotes a set, and that the sentence identifies one element in a set. This is why we call this type of predication 'classif ying predication'.

Let us now formulate the property-theoretic rule of predication, which we assume to underlie adjectival predicates. Insofar as adjectives must combine with entity-denoting expressions to yield sentences, they are expressions of type $<\mathrm{e}, \mathrm{t}\rangle$ (functions from entities into truth-values), but they do not denote sets. Rather, their semantic composition relies on a predication rule that introduces the predicate HAVE and a property $\mathrm{P}_{\mathrm{Adj}}$, which is an entity-correlate of the adjective. The property-theoretic rule of predication given in (23) and illustrated in (24) is adapted from Larson and Segal (1995: 136).

\section{Attributive Predication}

(23) $\quad[$ [ DP is Adj] $]=1$

(24) John is intelligent.

$$
\text { iff [[DP]] has } \mathrm{P}_{\text {Adj }}
$$

$$
[[\text { John }]]=\lambda P P(j) \quad[[\text { intelligent }]]=I
$$


$[[$ John is intelligent $]]=1$ iff $[[J o h n]]$ has $P_{\text {intelligent }}$ iff $P_{\text {intelligent }} \in\{P, j$ has $P\}$

In informal terms, we can say that copula sentences built with an adjective Adj attribute the property $\mathrm{P}_{\text {Adj }}$ (i.e., a particular type of entity) to the individual denoted by the subject. If we use an set-theoretic notation, we have (25):

$$
[[\mathrm{DP} \text { is } \mathrm{Adj}]]=1 \quad \text { iff } \mathrm{P}_{\mathrm{Adj}} \in[[\mathrm{DP}]]
$$

To sum up, the main difference between the two rules of predication is that they reverse the direction of the relation $\in$. In the case of nominal predicates, we check whether the individual denoted by the DP subject is an element of the set denoted by NumP (classifying predication). Conversely, in the case of adjectival predicates, it is the DP subject which denotes a set (of properties) and we check whether the property (viewed as an entity) associated to the Adj is a member of the set of properties denoted by the subject DP (attributive predication).

\subsection{Back to the French Data}

Given our two rules of predication, the ungrammaticality of examples such as (15b)-(16b) can be understood as being due to a conflict between the attributive rule of predication, which is necessarily triggered by adjectives, and the intrinsic properties of $c e$. Our proposal is stated in (26):

(26) Ce can only denote entities (type e). It cannot be type-lifted to denote sets of properties.

The attributive rule of predication can apply only if the subject DP can be analyzed as denoting a set of properties (see (25)): in order to check whether the subject DP has the property denoted by the adjective, we need to know whether the property denoted by the adjective belongs to the set of properties denoted by the subject DP. This rule cannot apply to $c e$, because it cannot denote sets of properties (see (26)) $)^{5}$.

The examples built with nominal predicates are grammatical, because $c e$ is compatible with the set-theoretic rule of predication (classifying predication):

Ton neveu, c'est un orgueilleux.

'Your nephew, he is a proud man'

The sentence in (27) is true iff the individual denoted by ton neveu belongs to the set of individuals denoted by the predicate:

$$
[[\text { Ton neveu }]] \in\{\mathrm{x}: \text { orgueilleux }(\mathrm{x})\} \quad \text { (set of atomic individuals) }
$$

Note that $c e$ is grammatical in identity copula sentences such as (29), because such sentences do not rely on predication, but rather on the identity relation between the two individuals denoted by the subject DP and the proper noun: 
\{Lui, L'homme que Marie a rencontré\}, c'est Don Juan.

' $\{$ Him, The man who Marie met $\}$, he is Don Juan'

\section{Names of Role or Guise}

\subsection{The Alternation NP/NumP in Romance Languages}

It is often assumed that the presence or lack of the indefinite article in predicate position is due to some syntactic constraint, but doesn't play any semantic role (Partee 1987). This assumption is contradicted by languages such as French, in which a contrast between (30a) and (30b) has been observed (Laca and Tasmovski 1994, de Swart et al. 2005).
a. Jean est \{clown, danseur\}.
(professional)
b. Jean est un \{clown, danseur\}.
(not necessarily professional)

When they are used bare, nouns of role have a restricted meaning: they can only refer to professions, roles, functions, but not to occasional events or activities. Instead, the sentence (30b) is underdetermined and can refer to a profession or to a specific event. This contrast can be explained in our framework. In (30a), clown is a bare NP, which denotes a property and is analyzed by the rule of attributive predication. In (30b) on the other hand, a clown is a NumP, which refers to a set of individuals, and the sentence is analyzed in terms of classif ying predication.
a. Jean has the property of being a clown
b. Jean is an element of the set of clowns

We will first focus on the analysis of examples of the type in (30). We will come back to the use of names of role with an indefinite determiner in section 3.4.

\subsection{NPs in Predicate Position}

It is well known that in Romance languages, a restricted class of common nouns can be used bare, i.e., without any determiner (a.o., Kupferman 1979, Pollock 1983, Boone 1987, Laca and Tasmowski 1994, Roy 2001, Matushansky and Spector 2004, de Swart and al. 2004). It is usually observed that the class of nouns which can be bare in predicate position includes professions, titles and functions (see (33)).

(33) Professions (médecin 'doctor', avocat 'lawyer'...), titles (prince 'prince', baron 'baron', roi 'king'...), hobbies (chasseur 'hunter', alpiniste 'climber',...), functions (président 'president', ministre 'minister', sénateur 'senator'...), status (étudiant 'student', $S D F$ 'homeless'...) 
Roy (2001) has observed that this class is larger and she claims that every noun which has an event variable can be used bare. This generalization accounts for the predicative use of bare nouns such as passager 'passenger', but we find it difficult to reduce professions, titles and functions to events. Moreover, Roy does not account for bare uses of complex expressions such as fils d'avocat 'son of lawyer'. We would like to propose another generalization: the nouns which can be bare are non sortal nouns. This caracterization is negative but it is new. We hope that further research will permit to determine positive criteria of this class.

Among non sortal nouns, we distinguish professions, titles and functions, which denote properties, event nouns such as passenger, and relational nouns built with a PP such as ami avec Pierre. The relevant characteristics of these nouns is that they don't possess the identity condition that determines when two objects to which the predicate applies count as the same object or as different objects (Geach 1962, Larson and Segal 1995). Only sortal nouns verify this condition on identity. We have already seen (section 1.4.) that relational nouns, when they are saturated from the outside, behave differently from sortal nouns and can be bare. Something similar can be said about nouns such as passenger, which are analyzed by Larson (1998) as two-place predicates, taking two arguments, an individual and an event. It has been observed by Gupta (1980) that this kind of nouns have complex identity condition. In the case of passenger for instance, one has to distinguish between the person and the flight: one and the same individual taking two different flights counts as one and the same person but as two distinct passengers. Event nouns, like relational nouns, can be bare in predicate position, when their argument positions are saturated outside the NP.

Jean est passager $\{$ ?du / à bord du $\}$ vol $n^{\circ} 345$.

Jean is passenger $\{$ of $/$ on $\}$ flight $n^{\circ} 345$

To sum up, we claim that all and only non sortal nouns can be used bare in predicate position. Our thesis is that they denote properties (primitive entities), either of individuals (nouns of role) or of events (relational nouns, event nouns). Conversely, sortal nouns must be used with an indefinite determiner. Examples (35)-(36) show that nouns of role are distinct from sortal nouns (such as child) when they are used bare, but become similar to sortal nouns, when they are governed by an indefinite. An explanation of this fact will be proposed in section 3.4 .

(35) a. Jean a été trois fois danseur. Jean has been three times dancer

b. Jean est professeur le jour, danseur la nuit Jean is teacher by day, dancer by night

a. * Jean a été trois fois \{un danseur, un enfant\} Jean has been three times a dancer, a child\}

b. * Jean est un professeur le jour, un danseur la nuit Jean is a teacher by day, dancer a by night

c. * Jean est un enfant le jour, un adulte la nuit. 
Jean is a child by day, an adult by night

\subsection{Simple vs. Complex Properties}

In our framework, bare nouns in predicate position are analyzed as expressions that denote properties. To attribute a property to an entity, one can either use an adjective, or a noun of guise such as dancer, or a complex expression which denotes a complex property. There are different ways of building complex properties. We describe here three different possibilities, which are perhaps non exhaustive.

The first type of complex property is shown in (37a-b), where the noun of guise is modified either by another noun preceded by a functional preposition (see (37a)) or by a postnominal adjective, as in (37b):
a. chanteur / chanteur de jazz
'singer / singer of jazz'
b. passager / passager clandestin
'passenger / passenger underground'

The second way of building complex properties relies on kinship nouns. Because they are relational nouns, such nouns cannot be used without a complement, but contrary to current assumptions, they are not necessarily saturated by an individual, but may also be saturated by properties. Depending on whether they are saturated by a property or by an individual, kinship nouns must be used without or with an article:

$$
\begin{aligned}
& \text { Jean est fils }\{* \text { de Marie, *d'un avocat\}. } \\
& \text { Jean is son }\{\text { of Mary, of a lawyer } \\
& \text { Jean est le fils }\{\text { de Marie, d'un avocat\}. } \\
& \text { Jean is the son } \text { \{of Mary, of a lawyer }
\end{aligned}
$$

Given the proposal made in this paper, the data in (38)-(39) can be analyzed in terms of attributive predication: fils d'avocat 'son of lawyer' denotes a complex property (hence the lack of article) that is attributed to Jean. Intuitively speaking, we can say that Jean inherits the lawyer quality from his father.

In our framework, we can assume that kinship nouns such as fils may denote not only a relation between two individuals but also a relation between an individual and a property (role/guise) (cf (40a)). Correspondingly, fils d'avocat in (38) denotes a complex property, obtained by applying a function (fils) to a property (avocat) (see (40b)).
a. $\lambda x \lambda P$ fils $(x, P)($ avocat $) \mathrm{j}$
b. $\lambda x$ fils ( $x$, avocat $) j$

The third way of building a complex property consists in modifying an adjective by a noun of guise:

(41) Jean est mauvais danseur. 
We claim that nouns of role can be taken to denote both a property and a property modifier. In example (41), which illustrates the latter case, the noun of guise is analyzed as a property modifier rather than as a property: the property attributed to Jean is not the property of being a dancer, but the property of being bad, as a dancer. This analysis presents two advantages compared to some other recent proposals (Matushansky and Spector 2004, de Swart et al. 2005). First, we can explain why danseur in (41) does not have the restricted meaning of professional dancer (compare bare Ns, which have only the restricted meaning): (41) can be understood as meaning 'Jean is bad when he dances', and not necessarily as 'Jean is a professional dancer who dances badly'. Following Fox (2000), we will formalize property modifiers in the framework of Property Theory.

$$
\begin{array}{ll}
\text { danseur as property } & : \text { property constant } D \\
\text { danseur as a property modifier } & : \lambda \mathrm{P} \lambda \mathrm{x}(\mathrm{D}(\mathrm{x}) \rightarrow(\mathrm{x} \text { has } \mathrm{P}))
\end{array}
$$

(43) translates the fact that danseur can modify a property $P$ and yields another property. This new property can be attributed to an individual $x$ if and only if, when $x$ has the property $D$, i.e. when $x$ dances as a professional dancer or not, $x$ also has the property $\mathrm{P}$. Thus (41) can be analyzed as an attributive predication in which mauvais danseur denotes a complex property that is attributed to Jean.

The second advantage of our proposal is that it can be extended to cover examples of the type shown in (44), which are usually analyzed as lexicalizations or idioms. Within our account, they can be instead analyzed in terms of property modification:
a. Jean est $\{$ beau, gentil, beau et grand\} garçon.
b. Marie est \{vieille fille, jeune grand-mère\}
c. Jean est $\{$ simple soldat / petit commerçant $\}$.

\subsection{Names of Role and the Projection of Number}

We can now come back to the analysis of names of guise used with an indefinite. We consider that (45) illustrates a case of classifying predication, in which the DP un danseur denotes a set of individuals rather than a property.
a. Jean est un danseur / Jean is a dancer
b. Jean est un bon danseur / Jean is a beautiful dancer.

Our hypothesis is that in these sentences, the sortal noun individual or human is covertly present, and that the NP governed by Number is not the noun danseur, but the covert noun individual. (45a) will be analyzed as meaning 'Jean belongs to the set of individuals who are dancers', and (45b) as 'Jean belongs to the set of individuals who are beautiful as dancers'. So in (45a), the noun dancer denotes a property, and in (45b), beautiful dancer denotes a complex property (the adjective beautiful denotes a property whereas the noun dancer denotes a property modifier). 
To conclude, let us briefly compare our proposal to that of de Swart et al. The syntactic assumptions on which our analyses are built are similar: we consider that bare nouns in predicate position lack Det and Num projections and correlatively denote properties. But there are two important differences between the two analyses: (i) de Swart et al. do not postulate two different rules of predication, but only one, the standard set theoretic one; therefore they have to postulate a covert operator CAP which maps the property denoted by the bare noun to a set, the set of institutional owners of this property. (ii) de Swart et al. do not account for the generalization from names of role to complex expressions such as fils d'avocat nor for the correlation between bare nouns in predicate position and adjectives.

\section{Bare Singulars and Bare Plurals: Properties and Sets}

In this section we will argue that the distinction proposed here between qua-set predicates and qua-property predicates can help us refine the analysis of existential bare plurals, by comparing them with bare singulars. We will thus be led to restate the property-analysis of bare plurals in terms of sets of individuals and to correlate genuine property-denotation (which is characteristic of BSs) with a rule of Predicate Modification.

\subsection{The Distribution of Bare Singulars}

In languages with articles, count plural nouns (as well as mass nouns, which are not illustrated here) can be productively used bare, whereas count singulars normally carry an indefinite article. There are, however, certain contexts in which even count singulars can appear bare. This state of facts holds in Hungarian, Albanian, Mainland Scandinavian (Danish, Norwegian), as well as Romance languages such as Romanian and Spanish. Our main aim will be to explain why the distribution of bare singulars is much more restricted than that of bare plurals and (BSs and BPs, henceforth).

The examples in (46), which are adapted from Laca's (1999) Spanish examples, illustrate some of the highly restricted contexts in which count singulars can appear bare in Romanian (and Spanish): ${ }^{6}$

(46) a. Ion are \{casă, maşină, copil mic, paşaport, bucătăreasă\}. John has \{house, car, child young, passport, cook\}

b. Ion şi-a cumpărat casă. John to-himself has bought house.

c. Ion caută \{secretară, nevastă, femeie, profesor, bucătar\}. John is looking for \{secretary, wife, woman, teacher, cook\}

d. Maria poartă \{pantalon, pălărie, uniformă, poşetă, cravată, cămaşă . Mary wears \{trouser, hat, uniform, handbag, tie, shirt\} 
It is not easy to characterize these examples in a unitary manner. It is much easier to give the list of the verbs that allow BSs in object positions: HAVE and acquisition verbs (see (46a-b)), intensional verbs selecting relational nouns (see (46c)), a purta 'wear' (see (46d)). ${ }^{7}$ It is not our aim to account for these lexical restrictions. Crucial here is the observation that only a very limited number of verbs allow BS objects.

The distribution of bare plurals (BPs) in object position is much freer (see (47)). The examples in (49) show furthermore that BSs cannot occur in subject positions, whereas BPs can do so (modulo various constraints): ${ }^{8}$

a. Ion a \{citit, scris\} \{poezii, romane\}. (object BPs) John \{read, wrote $\}$ poems, novels

b. Copiii au văzut filme. The children saw movies

a. *Ion a \{citit, scris\} \{poezie, roman\}. (object BSs; same glosses as (47))

b. * Copiii au văzut film.

*In grădină \{se plimba leu, se plimbau lei\}.

In garden \{strolled lion, strolled lions\}

Note finally that although English is like Romance languages (other than French) in allowing existential BPs, it differs from them insofar as it does not allow BSs in object positions. The Romanian examples given above can only be translated in English with an indefinite singular or a bare plural.

\subsection{Weak Bare Plurals: Existential Quantification and Set-Denotation}

We have so far shown that the distribution of BSs is more restricted than that of BPs. These differences clearly indicate that the analysis of BSs must be kept distinct from that of BPs. The first question to ask then is why the semantic rule by which BPs compose with a predicate cannot apply to BSs. We will leave aside the kind-analysis of weak bare plurals (Carlson 1977, Chierchia 1998) ${ }^{9}$ and concentrate on the so-called 'property-analysis' (a.o., van Geenhoven 1996, Dobrovie-Sorin 1997, Dobrovie-Sorin and Laca 2003, Farkas and de Swart 2003, Chung and Ladusaw 2004). Although this analysis crucially differs from Carlson's (1977) proposal regarding the semantic type of existential BPs, it is based on Carlson's hypothesis that the existential quantifier is not supplied by the BP itself, but rather by the verbal predicate. The basic idea is that certain predicates, e.g., sleep, dance, can be represented in two ways. Under their canonical representation they are one place predicate which must be saturated by e-type constituents (see (50a)). Under their 'existential' version, they are functions which take a property as their argument and correlatively involve an existential quantifier over the corresponding argument position (see (50b)).
a. $\lambda x \cdot \operatorname{sleep}(x)$
b. $\lambda P . \exists x(\operatorname{sleep}(x) \wedge P(x))$ 
We can now represent examples such as (51) as shown in (52), where the predicate sleep, represented as in (50b), takes as an argument the property denoted by niños 'children'. The representation in (52b) is obtained by $\lambda$-conversion from (52a):
Duermen niños.
Spanish sleep children
'Children are sleeping'
a. $\lambda P . \exists x[\operatorname{dormir}(x) \wedge P(x)]($ niños)
b. $\exists x[\operatorname{dormir}(x) \wedge \operatorname{niños}(x)]$

This analysis cannot explain why bare singulars are not allowed in all the contexts in which bare plurals are: given the representation of existential predicates given in (50b), they are predicted to combine with both bare plurals and bare singulars, since both types of bare nouns are currently assumed to denote properties.

Let us now try to solve this problem by using the distinction proposed in this paper between property-denotation and set-denotation. Note indeed that the formula given in (50b) is underdetermined with respect to this distinction: $P(x)$ can correspond either to attributive predication $(x$ has $P$ ) or to classifying predication $(x \in\{x: x$ is $P\})$. The distinction between these two rules of predication correlates with the distinction between bare singulars and bare plurals: bare singulars denote properties and correlatively rely on attributive predication, whereas bare plurals denote sets (of groups), and correlatively rely on classifying predication. The result that we are looking for is that bare singulars cannot saturate formulas of the type in (50b). And since bare singulars correlate with attributive predication, what we need to say is that existential quantification is incompatible with attributive predication. This incompatibility is possibly related to the well-known generalization that the subject of certain predicates (analyzed here as denoting properties and as correlatively inducing the attributive rule of predication) must be existentially presupposed. The assertion of set-membership (classifying predication), on the other hand, can combine with the assertion of existence, hence the possibility of combining bare plurals (which denote sets) with existential predicates (which induce the assertion of existence). In sum, the reason why existential predicates (i.e., those predicates that supply an existential quantifier) can combine with bare plurals but not with bare singulars is that the assertion of existence allows set-denoting arguments, but disallows property-denoting arguments.

\subsection{Bare Singulars: Property-Denotation and Predicate-Modification}

What is then the analysis of examples such as (53), where BSs occur in object positions? In line with other recent proposals, we can assume that the semantic composition of BSs relies on a rule of Predicate Modification. For concreteness we will use Dayal's (2003) rule of Pseudo-incorporation, ${ }^{10}$ which is based on the idea that certain transitive verbs can be represented as 'incorporating predicates': 

a. $\lambda x \lambda y \lambda e[\mathrm{~V}(\mathrm{e}) \wedge \mathrm{Ag}(\mathrm{e})=\mathrm{y} \wedge \mathrm{Th}(\mathrm{e})=\mathrm{x}]$
b. $\lambda \mathrm{P} \lambda \mathrm{y} \lambda \mathrm{e}[\mathrm{P}-\mathrm{V}(\mathrm{e}) \wedge \mathrm{Ag}(\mathrm{e})=\mathrm{y} \wedge$ Appropriately Classificatory (e)]

(53a) represents a transitive verb, and (53b) represents the incorporating version of the same verb, which is obtained by replacing the Theme argument with a place-holder for a predicate-modifier notated $\mathrm{P}$, which is to be filled by BSs. Under this analysis, the relation between read and book-read is akin to the relation between cook and boil (manner-of-cooking verb). The restriction to 'appropriately classificatory' (Dowty 1979) events is meant to account for the fact that V + BS sequences cannot refer to particular events, but instead must refer to types of events (which are culturally stable). The formula in (53b) is not sufficiently explicit. It seems clearer to revise it as shown in (53c):

$$
\text { c. } \lambda \mathrm{P} \lambda \mathrm{y} \lambda \mathrm{e}[\mathrm{V}(\mathrm{e}) \wedge \mathrm{Ag}(\mathrm{e})=\mathrm{y} \wedge \mathrm{Th}(\mathrm{e})=\mathrm{x} \wedge \mathrm{x} \text { has } \mathrm{P} \wedge \text { App. Classif. (e)] }
$$

Since the formula in (53c) does not contain an existential quantifier, the attributive rule of predication ( $x$ has $P$ ) is allowed. Hence the possibility of BSs, which denote properties, and as such necessarily rely on the attributive rule of predication.

It is important to stress that although both BPs and BSs are constrained by the lexical properties of the main predicate, the constraints are different: BS denote properties, and as such they can combine with incorporating predicates, but not with existential predicates; BPs denote sets, and as such they can combine with existential predicates, but not with incorporating predicates.

\section{Endnotes}

"We are grateful to Danièle van de Velde, who participated to several working sessions on the issues discussed in this paper.

${ }^{1}$ This requirement also holds for mass nouns, e.g., butter, which can be assumed to be governed by a covert functional category labelled Quantity occupying the same syntactic position as Number.

${ }^{2}$ The examples in $\left(7 a^{\prime}-c^{\prime}\right)$ are parallel to $(7 a-c)$ from the point of view of overt syntax, but they presumably differ regarding their syntactic category: singular indefinites, bare plurals and bare mass nouns are NumPs in predicate position and DPs in argument position.

${ }^{3}$ There is no English counterpart for the use of $c e$ in these French examples. This $c e$ should be kept distinct from another ce, which translates as this / that in English, e.g., C'est beau 'That's wonderful'.

${ }^{4}$ What we call 'anaphoric' $c e$ is preceded by or else presupposes a discourse antecedent: in (15) the antecedent belongs to a previous sentence, and in (16) it is a left dislocated Topic. Our investigation does not bear on other varieties of $c e$, e.g., examples of the following type, in which $c e$ is clearly not anaphoric and might be called 'deictic': 
a. Mais qu'est-ce que c'est? 'But what is it?'

b. Je ne sais pas, mais c'est \{mou, *du mou, beau, brulant .

'I don't know, it (CE) is \{soft, DU soft, beautiful, hot \}'

${ }^{5}$ The constraint on the use of anaphoric ce disappears in generic contexts such as Un enfant, $\{c e, c ̧ a\}$ n'est pas intelligent 'Children are intelligent'. Our suggestion is that in this case, $c e / c ̧ a$ (or rather its antecedent) denotes a kind: since a kind is an entity which is basically defined as a set of properties, the attributive rule of predication can apply.

${ }^{6}$ For a more detailed presentation of the data, see Dobrovie-Sorin and Bleam (2005).

${ }^{7}$ This list is not exhaustive: we can add at least two isolated verbs, $a$ folosi 'use', $a$ conduce 'drive', as well as light verbs, idioms and proverbs.

${ }^{8}$ In Romance languages, bare plurals are not allowed in the preverbal position, unless they are coordinated or modified (see Dobrovie-Sorin and Laca (2003), Longobardi (1994) and references quoted there).

${ }^{9}$ For arguments against this analysis, see, a.o., Dobrovie-Sorin and Laca (2003).

10 Farkas and de Swart's (2003) rule of Theta-Unification and Chung and Ladusaw's (2004) are different implementations of the same basic type of rule.

\section{References}

Baker, Mark: 2003, Lexical Categories: Verbs, Nouns and Adjectives, Cambridge University Press, Cambridge Studies in Linguistics 102.

Boone, Annie: 1987, 'Les Constructions Il est linguiste/C'est un linguiste', Langue Française 75, 94-106.

Carlson, Greg: 1977, Reference to Kinds in English. Ph.D. dissertation, University of Massachusetts. Published in 1980, Garland, New York.

Chierchia, Gennaro: 1982, 'Nominalization and Montague Grammar: a semantics without types for natural languages', Linguistics and Philosophy 5, 303354.

Chierchia, Gennaro: 1985, 'Formal Semantics and the Grammar of Predication', Linguistics Inquiry 16, 417-443.

Chierchia, Gennaro: 1998, 'Reference to Kinds across Languages'. Natural Language Semantics 6, 339-405.

Chierchia, Gennaro and Raymond Turner: 1988, 'Semantics and Property Theory', Linguistics and Philosophy 11, 261-302.

Chung, Sandra and Williams Ladusaw: 2004, Restriction and Saturation, MIT Press.

Dayal, Veneeta: 2003, 'A Semantics for Pseudo Incorporation', ms.

Dobrovie-Sorin, Carmen: 1997, 'Types of Predicates and the Representation of Existential Readings', in A. Lawson (ed.) Proceedings of SALT VII, Cornell University Press, Ithaca, New York. 
Dobrovie-Sorin, Carmen and Brenda Laca: 2003, 'Les noms sans déterminant dans les langues romanes', in D. Godard (ed.) Les langues romanes. Problèmes de la phrase simple, CNRS Editions, Paris.

Dobrovie-Sorin, Carmen and Tonia Bleam: 2005, 'Noms nus, nombre et types d'incorporation', in C. Dobrovie-Sorin (ed.) Généricité et détermination nominale, Presses Universitaires de Vincennes.

Dowty, David: 1979, Word Meaning and Montague Grammar. Reidel, Dordrecht.

Farkas, Donka and Henriette de Swart: 2003, The Semantics of Incorporation. CSLI Publications, Stanford.

Fox, Chris: 2000, The Ontology of Language. Properties, Individuals and Discourse, CSLI Publications, Stanford.

Geach, Peter: 1962, Reference and Generality, Comell University Press, Ithaca.

Gupta, Anil: 1980, The Logic of Common Nouns, Yale University Press, New Haven.

Kupferman, Lucien: 1979, 'Les Constructions Il est un médecin/C'est un médecin: Essai de solution', Cahiers linguistiques 9, 131-164.

Laca, Brenda: 1999, 'Presencia y ausencia de determinante, 891-929., in I. Bosque and V. Demonte (eds.), Gramática descriptiva de la lengua española, Real Academia Española, Collección Nebrija y Bello, vol. 1, Espasa Calpe, Madrid.

Laca, Brenda and Liliane Tasmovski: 1994, 'Le pluriel indéfini de l'attribut métaphorique', Linguisticae Investigationes XVIII(1), 27-48.

Larson, Richard and Gabriel Segal: 1995, Knowledge of Meaning. Cambridge, MA, MIT Press.

Larson, Richard: 1998, 'Events and modification in nominals', in D. Strolovitch and A. Lawson (eds.) Proceedings from SALT VIII. CLC Publications, Ithaca, New York, 145-168.

Longobardi, Giuseppe: 1994, 'Reference and Proper Names', Linguistic Inquiry 25, 609-665.

Matushansky, Ora and Benjamin Spector: 2004, 'Tinker, Tailor, Soldier, Spy', talk given at Sinn und Bedeutung 9.

Partee, Barbara: 1987, 'Noun Phrase and Type-Shifting Principles', in Groenendijk et al. (eds), Studies in Discourse Representation Theory and the Theory of Generalized Quantifiers, Dordrecht, 115-143.

Pollock, Jean-Yves: 1983, 'Sur Quelques Propriétés des Phrases Copulatives en Français', Langue Française 58, 89-125.

Roy, Isabelle: 2001, 'Predicate Nominals in French', ms, USC.

de Swart, Henriette, Yoad Winter and Joost Zwarts: 2005, The Interpretation of Bare Predicate Nominals in Dutch, Ms.

Tamba, Irène: 1983, 'Pourquoi dit-on "Ton neveu, il est orgueilleux" et "Ton neveu, c'est un orgueilleux"', L'information grammaticale 19, 3-10.

van Geenhoven, Veerle: 1996, Semantic Incorporation and Indefinite Descriptions: Semantic and Syntactic Aspects of West Greenlandic Noun Incorporation, Ph.D. dissertation, Universität Tübingen. 